A non-contact method for spatially localized sedimentation of particles from liquid suspensions using Marangoni forces

This article has been downloaded from IOPscience. Please scroll down to see the full text article.

2011 J. Micromech. Microeng. 21115028

(http://iopscience.iop.org/0960-1317/21/11/115028)

View the table of contents for this issue, or go to the journal homepage for more

Download details:

IP Address: 141.211.173.82

The article was downloaded on 06/04/2012 at 15:58

Please note that terms and conditions apply. 


\title{
A non-contact method for spatially localized sedimentation of particles from liquid suspensions using Marangoni forces
}

\author{
Erwin Hendarto and Yogesh B Gianchandani \\ Department of Electrical Engineering and Computer Science, University of Michigan, Ann Arbor, \\ MI 48109, USA \\ E-mail: erwinh@umich.edu
}

Received 20 July 2011, in final form 22 September 2011

Published 20 October 2011

Online at stacks.iop.org/JMM/21/115028

\begin{abstract}
This paper presents the directed sedimentation of suspension particles in a thin layer of liquid

$(\leqslant 1 \mathrm{~mm})$ onto a featureless glass substrate by Marangoni flows. A programmable $16 \times 8$ array of surface mount resistors suspended $0.1-2 \mathrm{~mm}$ above the liquid provides dynamic millimeter-sized heat sources to locally heat the liquid surface to temperatures from approximately 28.5 to $36.5^{\circ} \mathrm{C}$. The heaters in this array can be activated independently by a graphical user interface, creating surface tension gradients along the liquid surface. The resulting Marangoni flows direct spatially localized particle sedimentation on the substrate. The resultant sedimentation patterns and accumulation levels depend on factors such as the temperature gradient at the liquid surface, number of active heaters and type of liquid used. For example, when a single heater is activated, a liquid surface temperature elevation of $6.9{ }^{\circ} \mathrm{C}$ results in a localized sedimentation of suspended weed pollen Kochia scoparia $(\Phi=25 \mu \mathrm{m})$ in silicone oil DC-704 over a region of $2.9 \mathrm{~mm}^{2}$ that is centered directly beneath the active heater. This sedimentation method is a contactless technique, which reduces the likelihood of sample contamination.
\end{abstract}

(Some figures in this article are in colour only in the electronic version)

\section{Introduction}

Low cost diagnostic systems that offer high sensitivity and quick response are increasingly important for healthcare monitoring [1, 2] and environmental monitoring [3]. Such systems utilize microfluidic technologies to manipulate particles or liquids. Often, particle trapping, separation and deposition are necessary to increase the concentration level of the particles so that detection and accurate analysis are possible. As these systems progressively decrease in size, surface phenomena become more dominant and play important roles in microfluidic applications, influencing particle transport, trapping, mixing, reaction and separation. The Marangoni effect develops as a result of surface tension variations at the liquid/gas interface caused either by a temperature gradient or concentration gradient in the liquid, and is an example of a surface phenomenon. This phenomenon is known to be responsible for many common occurrences, such as the 'tears of wine' [4] and superspreading of solution [5]. In several industrial processes such as the floating-zone process for crystal growth, the Marangoni effect also plays a critical role [6]. As a result, the Marangoni effect has been studied extensively [7-13]. Factors which influence Marangoni flow such as presence of turbulence [14] and liquid depth [15] have also been investigated.

The Marangoni effect, when induced by a temperature gradient, is also known as thermocapillarity. It is considered as a form of thermophoresis when the liquid flow and corresponding particle movement are induced by such a temperature gradient $[16,17]$. When temperature variation is imposed on a liquid surface, surface tension gradient develops at the liquid surface. This results in liquid motion along the liquid/gas interface, and flow in the opposite direction in the bulk liquid. Such liquid motion is referred to as Marangoni flow. Marangoni force has been utilized for transporting nanoliter amounts of liquids over a large area [18], and droplet 
displacement and switching in a bifurcating microfluidic channel [19]. One method to generate Marangoni flow is to subject a liquid surface to a micrometer scale temperature source suspended above the liquid. Different shapes of heat sources in the micrometer range have been utilized to generate flows capable of manipulating micro particles and droplets [20]. Marangoni flow has also been employed to perform droplet actuation by programmable manipulation using a 128 pixel heater array suspended $0.1-2 \mathrm{~mm}$ above the liquid surface [21]. This paper ${ }^{1}$ describes the investigation of the directed sedimentation of suspension particles in a liquid onto a featureless glass substrate by Marangoni flows using this 128 pixel heater array. Figure 1 $(a)$ shows the crosssection of a 3D schematic diagram of particle sedimentation by Marangoni cells and part of the heater array suspended above the liquid. By activating a particular heater in the heater array, a temperature gradient is created on the surface of a thin liquid layer directly below the heater. This results in surface tension gradient, which generates Marangoni flows capable of directing particles to accumulate at desired locations on a blank glass substrate in a contactless manner. The Marangoni sedimentation technique reduces the need for costly fabrication processes and allows spatially localized particle sedimentation to be performed on any substrate.

Section II presents the theoretical and simulation modeling of Marangoni flow in a bulk liquid induced by a millimeter-sized heat source in close proximity to the liquid surface. Section III describes the experimental results, showing the various sedimentation patterns formed by different conditions. The discussion and conclusion are presented in section IV.

\section{Theoretical modeling}

The heat generated from the heat source travels through the air gap and increases the liquid surface temperature directly below the heat source in a spatially localized manner. A temperature gradient is created at the liquid surface, resulting in a surface tension gradient. The corresponding thermocapillary shear stress, $\tau_{s}$, is proportional to the temperature gradient, $\nabla T_{s}$ $[23,24]$ :

$$
\tau_{s}=\mu \frac{\mathrm{d} \overrightarrow{u_{s}}}{\mathrm{~d} \vec{N}}=\sigma_{T} \nabla T_{s} .
$$

In this equation, $\mu$ is the dynamic viscosity of the liquid, $\overrightarrow{u_{s}}$ is the tangential surface velocity vector, $\vec{N}$ is the surface normal vector and $\sigma_{T}=\frac{\partial \sigma}{\partial T}$ is the surface tension temperature coefficient. As the direction of the shear stress and liquid flow are from a region of low surface tension (high temperature) to that of a high surface tension (low temperature), Marangoni flow at the surface of the liquid is directed away from the heat source. This produces subsurface flows toward the heat source in the bulk liquid. The surface and subsurface flows together form the Marangoni cell, transporting suspended particles in a toroidal pattern. This phenomenon is depicted by figure $1(a)$.

A 3D simulation model is created using COMSOL Multiphysics ${ }^{\circledR} 3.5 \mathrm{a}$; it includes the heater array and its

\footnotetext{
1 Portions of this paper have appeared in conference abstract form in [22].
}
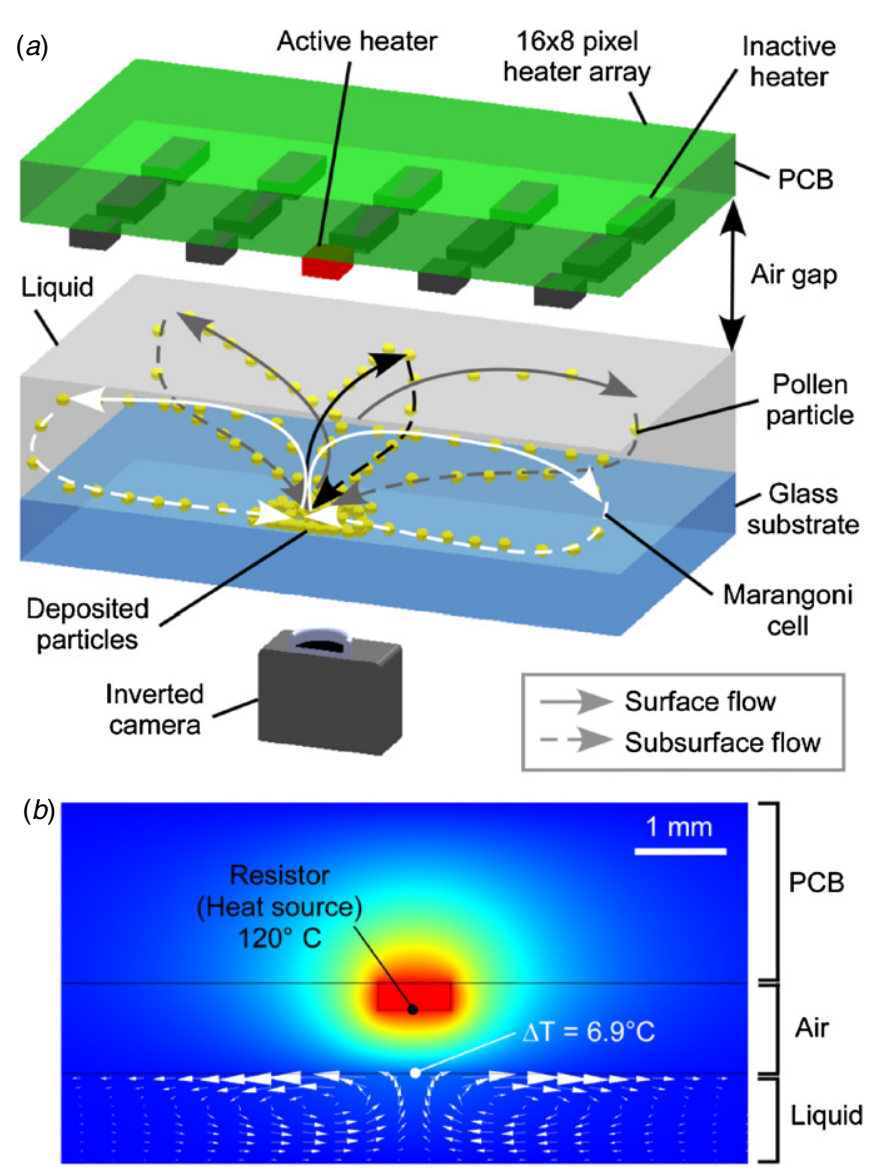

Figure 1. (a) Cross-sectional view of 3D schematic diagram of the experimental setup. (b) Simulation result (COMSOL Multiphysics ${ }^{\circledR}$ $3.5 a$ ) showing temperature distribution profile and generated Marangoni flow cells in silicone oil DC-704.

supporting printed circuit board (PCB), the air gap, and the liquid on the glass substrate as shown in figure 1(b). Power is supplied to the heater to achieve localized temperature elevation of $\approx 7{ }^{\circ} \mathrm{C}$ on the liquid surface. The liquid is assumed to be $1 \mathrm{~mm}$ deep silicone oil DC-704 (Dow Corning Corporation, Midland, MI) with properties summarized in table 1 [25]. Air is a relatively poor conductor of heat, with a low thermal conductivity of $0.025 \mathrm{~W} \mathrm{~m}^{-1} \mathrm{~K}^{-1}$. When the air gap between the heater and the liquid surface is $700 \mu \mathrm{m}$, the liquid surface temperature increase of $6.9{ }^{\circ} \mathrm{C}$ is obtained for a power level of $600 \mathrm{~mW}$, which elevates the surface of the resistor to $120{ }^{\circ} \mathrm{C}$ (this has been experimentally verified by measurements with a thermocouple as well as an infrared (IR) thermometer). Such temperature elevation can be achieved with a power of 150 and $80 \mathrm{~mW}$ when the air gap is reduced to 100 and $10 \mu \mathrm{m}$, respectively. Assuming that the sides of the liquid are at ambient temperature of $27^{\circ} \mathrm{C}$, a temperature gradient and surface tension gradient develop at the surface. In thin layers of liquids, the dominant driving force is the Marangoni effect, while buoyancy force and other bulk phenomena are smaller. In figure $1(b)$, the arrows show the resulting Marangoni surface and subsurface flows in silicone oil DC-704. Simulation results also show that the surface temperature of the liquid immediately below the resistor rises 
Table 1. Material properties of the liquids used in particle sedimentation: silicone oil DC-550 [26], silicone oil DC-704 [25] and electronic liquid FC-3283 [27].

\begin{tabular}{|c|c|c|c|}
\hline \multirow[b]{2}{*}{ Parameter } & \multicolumn{3}{|c|}{ Liquid } \\
\hline & $\overline{\mathrm{DC}}-550$ & DC-704 & $\overline{F C-3283}$ \\
\hline Density, $\rho\left(\mathrm{kg} \mathrm{m}^{-3}\right)$ & 1068 & 1070 & 1820 \\
\hline Heat capacity, $C_{p}\left(\mathrm{~J} \mathrm{~kg}^{-1} \mathrm{~K}^{-1}\right)$ & 1418 & 1542 & 1100 \\
\hline $\begin{array}{l}\text { Thermal conductivity, } \\
\kappa\left(\mathrm{W} \mathrm{m}^{-1} \mathrm{~K}^{-1}\right)\end{array}$ & 0.13 & 0.16 & 0.066 \\
\hline $\begin{array}{l}\text { Absolute viscosity, } \\
\mu\left(10^{-3} \mathrm{~kg} \mathrm{~m}^{-1} \mathrm{~s}^{-1}\right)\end{array}$ & 134 & 42 & 1.4 \\
\hline Kinematic viscosity, $\mu_{k}(\mathrm{cSt})$ & 125 & 39 & 0.75 \\
\hline $\begin{array}{l}\text { Surface tension temperature } \\
\text { coefficient, } \sigma_{T}\left(10^{-6} \mathrm{~N} \mathrm{~m}^{-1} \mathrm{~K}^{-1}\right)\end{array}$ & -69 & -35.6 & -48.3 \\
\hline $\begin{array}{l}\text { Thermal expansion } \\
\text { coefficient, } \alpha\left(10^{-6} \mathrm{~K}^{-1}\right)\end{array}$ & 750 & 950 & 1400 \\
\hline
\end{tabular}

proportionately as the heater temperature is increased or the air gap is decreased.

The particle velocity is the greatest at the liquid/gas interface, and drops toward the sides and bottom of the liquid. The subsurface flows of the Marangoni cells are able to create sweeping actions on the substrate which result in particles close to the glass substrate being transported across the substrate, localizing the sedimentation below the heat source where the subsurface radial flow converges and rises to the surface. This final location of the particles is independent of whether the sedimentation of the particles upon the substrate is caused by gravitational forces or particle-substrate interaction.

The type of liquid used in the experiment can also affect the resultant particle velocity, and hence the particle collection. Three kinds of liquids are used in this work, namely silicone oil DC-550 [26], silicone oil DC-704 [25] and electronic liquid Fluorinert $^{\mathrm{TM}}$ FC-3283 (3M Specialty Materials, St Paul, MN) [27] with some of the properties listed in table 1. Thermal conductivity values are generally available, but this value is not available for DC-704, so its value is estimated from a similar liquid. The surface tension temperature coefficients are calculated from the Eötvös equation [28]:

$$
\sigma_{T}=-\frac{k_{\gamma}}{V_{m}^{2 / 3}} .
$$

$k_{\gamma}$ is the Eötvös constant, and the value is $2.1 \times 10^{-7} \mathrm{~J} \mathrm{~K}^{-1}$ $\mathrm{mol}^{-2 / 3}$ for most liquids; $V_{m}$ is the molar volume of the liquid, which is obtained by dividing the molar mass of the liquid by its density. The molar volume of silicone oil DC-550 is not known, and its surface tension temperature coefficient is estimated from a similar liquid.

The particles used in this work are $\Phi=25 \mu \mathrm{m}$ weed pollen from Kochia scoparia (Sigma-Aldrich, St Louis, MO) [29]. Small, spherical particles reach a terminal or settling velocity due to gravitational force. The settling velocity, $V_{t}$, is given by Stokes' equation:

$$
V_{t}=\frac{2 r^{2} g\left(\rho_{s}-\rho_{f}\right)}{9 \mu}
$$

where $r$ is the radius of the particle, $g$ is the gravitational acceleration, $\rho_{s}$ is the density of a particle and $\rho_{f}$ is the density of the liquid. Even though every pollen particle is not perfectly spherical, this equation provides a reasonably accurate approximation of the settling rate [30]. Because of pollen grouping, natural differences among pollen particles, the existence of air molecules and variations in the water retention within the pollen, settling velocities of weed pollen vary widely [30, 31].

\section{Experimental results}

A $16 \times 8$ heater array is used to generate Marangoni flows in a thin layer of liquid, typically less than a millimeter deep. The heater array consists of $100 \Omega \# 0603$ surface mount resistors, each of size $1 \times 0.8 \times 0.35 \mathrm{~mm}^{3}$ placed at $1.9 \mathrm{~mm}$ pitch on a PCB. Each resistor can be switched on and off independently via a user interface written in LabView (National Instruments, Austin, TX). The range of the heater power used is usually less than $1.3 \mathrm{~W}$. A complete description of the design, fabrication and electrical circuitry of the heater array is given by Basu et al [21].

Figure 1(a) shows the 3D schematic diagram of the experimental setup. The weed pollen particles are mixed homogeneously in a carrier liquid. The experiments are performed on $100 \mu \mathrm{l}$ samples. The depth of the liquid mixture is in the range of 500-1000 $\mu \mathrm{m}$; the heater array with the resistors is suspended $700 \pm 100 \mu \mathrm{m}$ above the liquid surface. The heating is initiated immediately after the introduction of the suspension onto the substrate, so that most of the particles are still in suspension within the liquid and do not have sufficient time to settle onto the glass substrate. The results are visualized using an inverted camera located under the glass substrate. The programmable heater array produces various sedimentation patterns.

Experimentally measured temperatures of a single active heater at different powers are shown in figure 2. Power is supplied to a resistor for about $1 \mathrm{~min}$ before temperature measurement so that the resistor has sufficient time to reach thermal equilibrium. The range of the power applied to the heater is $0.15-0.6 \mathrm{~W}$. Based on simulation results, this provides liquid surface temperatures of 28.5 to $34.0^{\circ} \mathrm{C}$ below the heater at the $700 \mu \mathrm{m}$ separation in silicone oil DC-704. To ensure accuracy, the temperature of the suspended heaters is measured using two methods - a thermocouple (Omega Engineering Inc., Stamford, CT) and an IR thermometer (Optris LS, Micro-Epsilon Optris, Berlin, Germany). The temperature readings obtained by the two instruments are consistent, and the measured temperatures vary linearly with power within this range. The simulated liquid surface temperature rise directly below the active heater is also shown.

Figure 3 shows the sedimentation pattern resulting from an estimated liquid surface temperature of $28.5{ }^{\circ} \mathrm{C}$ directly below the heater. The sample was prepared with $5 \mathrm{mg}$ of weed pollen homogeneously mixed into $1 \mathrm{ml}$ of silicone oil DC-704. The weed pollen was randomly distributed in the liquid at the start of the experiment. When the center heater is initially activated, particle velocities are low, and particles distant from the central axis of the active heater tend to settle on the substrate according to the settling rate in 


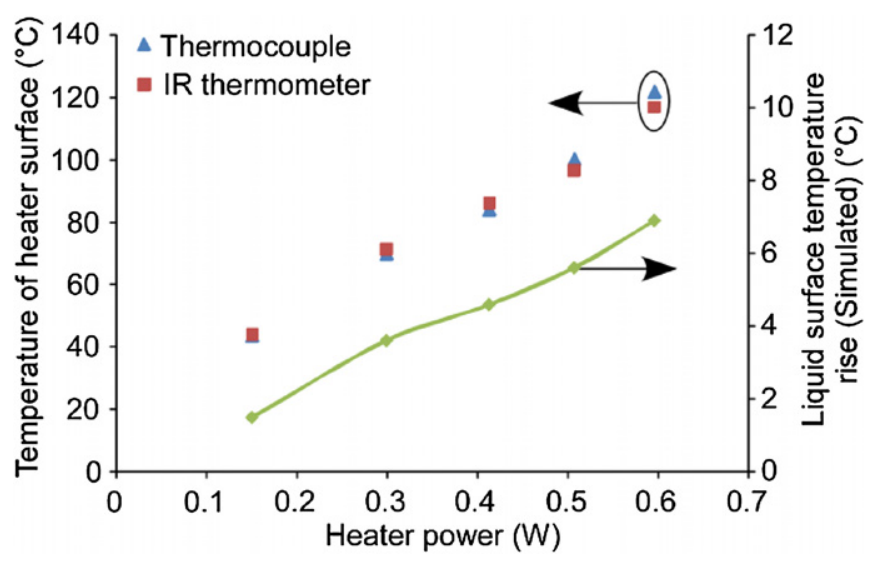

Figure 2. Temperature of a heater surface at various heater powers measured using a thermocouple and an infrared (IR) thermometer, and the resultant liquid surface temperature rise directly below the heater in silicone oil DC-704 obtained by simulation.

equation (3). There is insignificant change in the distribution of particles during the first 3 min of the experiment. After about $3 \mathrm{~min} 30 \mathrm{~s}$, particle movement is no longer observed. All the particles have settled onto the glass substrate, and despite the presence of the heat source, the particles remain stationary. No accumulation occurs as shown in figure 3(a). At the end of the experiment, the suspended heater array is raised but the liquid is not removed. The estimated number of particles below the left inactive heater, center active heater and right inactive heater per $200 \times 200 \mu \mathrm{m}^{2}$ in the first $4 \mathrm{~min}$ is shown in the graph of figure $3(b)$. It shows that the number of particles fluctuates and remains roughly constant over the time period despite temperature gradient developed at the liquid surface.

Figure 4 shows the temporal sequence of particle sedimentation starting with random distribution of weed pollen immersed in silicone oil DC-704 in figure 4(a). The same sample as that in figure 3 is used, with an estimated liquid surface temperature of $34.0{ }^{\circ} \mathrm{C}$. The accumulation begins to form $2 \mathrm{~min}$ after the start of the experiment. The deposit below the active heater after $2 \mathrm{~min}$ is shown in figure $4(b)$. Continued sedimentation in the next 8 min results in a pattern as seen in figure $4(c)$. The size of accumulation grows over time. The power was supplied for approximately $20 \mathrm{~min}$ until all particles that could be transported are localized to a region directly below the heat source. The final pattern is shown in figure $4(d)$. The deposit is largely concentrated in a region approximately $2.2 \mathrm{~mm}$ wide on its longer side, covering an area of $2.9 \mathrm{~mm}^{2}$ centered directly below the active heater. Some particles that randomly settle onto the glass substrate are not moved by the Marangoni cells.

The estimated pollen count directly under the center of the active heater and adjacent left and right inactive heaters per $200 \times 200 \mu \mathrm{m}^{2}$ is plotted for the initial $90 \mathrm{~s}$ of the experiment in figure $4(e)$. The high rate of sedimentation beneath the active heater is evident. The count was terminated at $90 \mathrm{~s}$ because manual counting became impractical. The numbers of particles below the left and right inactive heaters fluctuate depending on whether the random particles moving toward

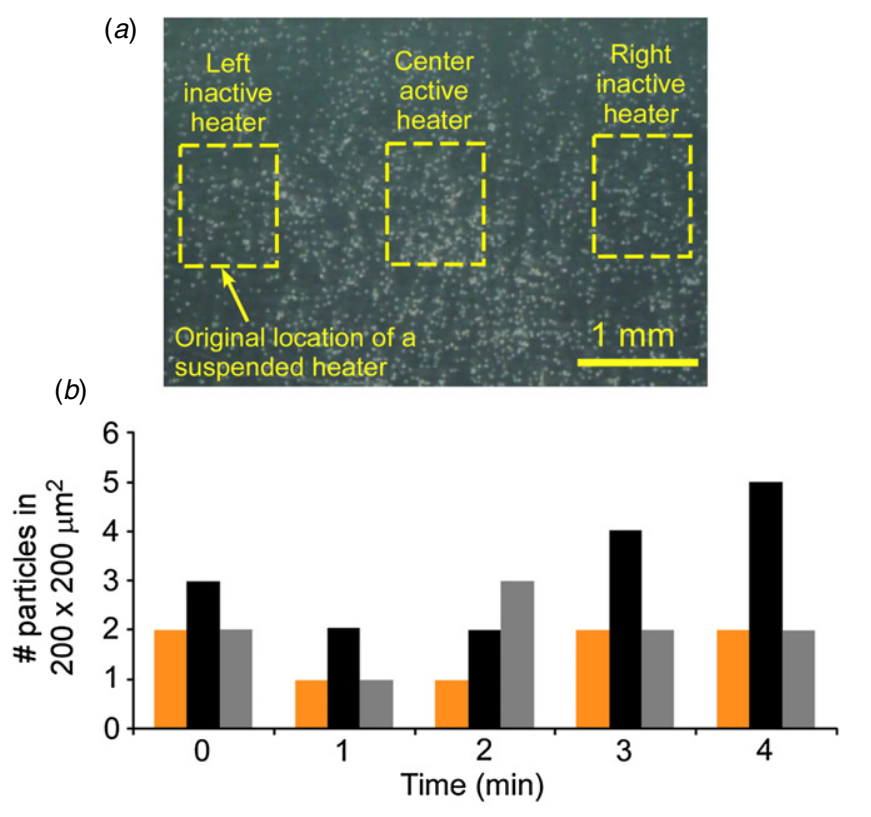

" Below left heater - Below center heater $=$ Below right heater

Figure 3. (a) No accumulation is observed in silicone oil DC-704 with an estimated liquid surface temperature of $28.5^{\circ} \mathrm{C}$ directly below the active heater. All the particles have settled onto the glass substrate after about $3 \mathrm{~min} 30 \mathrm{~s}$. Before taking the image, the suspended heater is raised but the liquid is not removed. $(b)$ Number of particles below the left, center and right heaters per $200 \times$ $200 \mu \mathrm{m}^{2}$ in the first $4 \mathrm{~min}$ of the experiment.

and away from the heat source come into the specified region where the count is taken. It can be observed from the graph that these numbers are generally constant and do not increase with time, showing that accumulation occurs only in the liquid region directly under an active heater.

The sedimentation pattern and accumulation level can be easily controlled. By activating different numbers of heaters simultaneously, different patterns and amount of collected particles can be attained, as shown in figure 5. Each heater is supplied with $0.6 \mathrm{~W}$, resulting in an estimated liquid surface temperature of 34.2 or $36.4{ }^{\circ} \mathrm{C}$ beneath the centroid when two or four heaters are activated, respectively. The test sample is the same as for figures 3 and 4 . The yellow rectangles in figure 5 identify the locations of the active heaters. More particles are collected when more heaters are active with the same initial concentration of suspension particles, and the accumulation covers a larger area. In figure $5(b)$, the deposit is concentrated in a region about $4 \mathrm{~mm}$ wide on its longer side, covering an approximate area of $7.9 \mathrm{~mm}^{2}$ centered between the four heaters.

The type of liquid used also affects sedimentation. Surface and subsurface flow velocities vary in different liquids such as silicone oil DC-550, silicone oil DC-704 and electronic liquid FC-3283. In this set of experiments, the three different liquids are used, and the concentration of the particles in each liquid is kept constant. Each experiment is run for about 20 min except that involving electronic liquid FC-3283. One heater is activated at a power of $0.6 \mathrm{~W}$. Figure $6(a)$ shows the resultant sedimentation in silicone oil DC-550. In this liquid, 


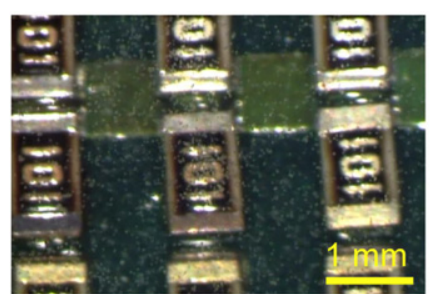

(a) $\mathrm{t}=1 \mathrm{~min}$

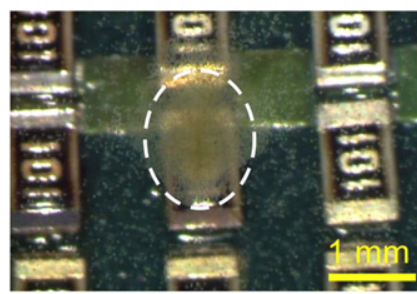

(c) $\mathrm{t}=10 \mathrm{~min}$

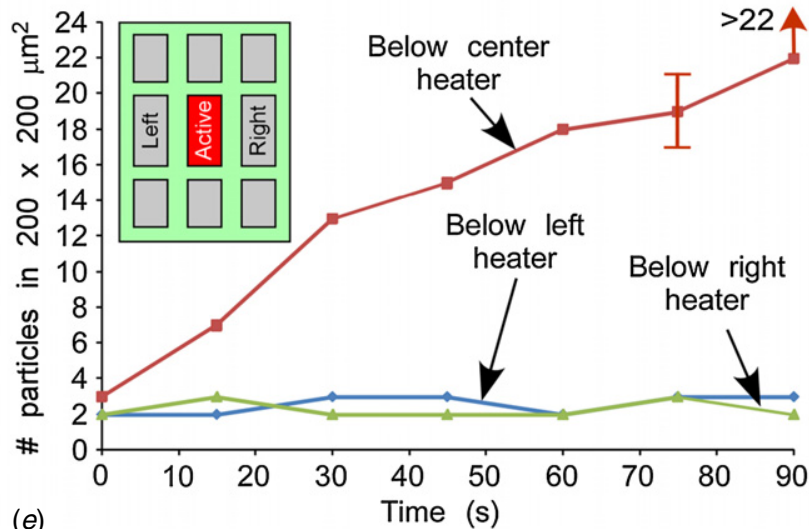

(e)

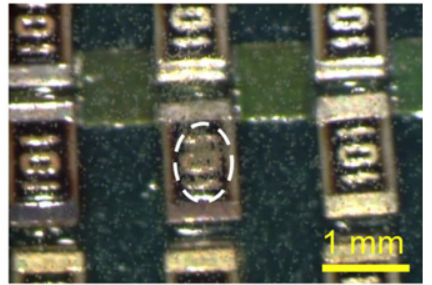

(b) $\mathrm{t}=2 \mathrm{~min}$

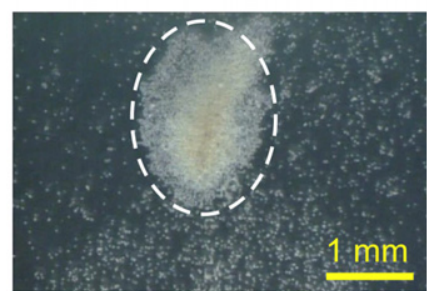

(d) $\mathrm{t}=20 \mathrm{~min}$

Figure 4. Sedimentation in silicone oil DC-704. The estimated liquid surface temperature is $34.0^{\circ} \mathrm{C}$. (a) Initial random distribution of particles immersed throughout the liquid $1 \mathrm{~min}$ into the experiment. (b) Particle sedimentation after 2 min showing a small amount of accumulation on the glass substrate below the active heater. $(c)$ Particle sedimentation after 10 min. $(d)$ Particle sedimentation after $20 \mathrm{~min}$. (e) Number of particles accumulated below the center active heater, left inactive heater and right inactive heater per $200 \times 200 \mu \mathrm{m}^{2}$.

the liquid surface temperature below the heater is estimated to be $35.5{ }^{\circ} \mathrm{C}$. Particle collection is limited to a small area of $1.3 \mathrm{~mm}^{2}$ below the heater, and the final pattern seems scattered. Figure $6(b)$ shows particle sedimentation in silicone oil DC704. In this liquid, more particles are collected from a larger area and form a more focused pattern. In electronic liquid FC-3283, the liquid surface temperature is estimated to be $29.7{ }^{\circ} \mathrm{C}$. Particles easily settle onto the glass substrate, and those that remain suspended move at a very high speed away from the heat source. No accumulation occurs as shown in figure $6(c)$.

\section{Discussion and conclusion}

In order to spatially localize a sedimentation, sufficient temperature gradient at the liquid surface must be achieved to generate Marangoni flows. This can be done by activating a single heater or multiple heaters to create temperature elevations at the liquid surface. A collection with a larger

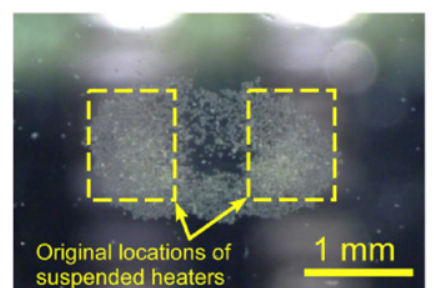

(a) Two active heaters

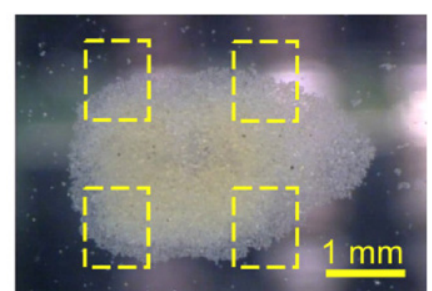

(b) Four active heaters
Figure 5. Formation of different patterns and amount of sedimentation in silicone oil DC-704 after approximately $15 \mathrm{~min}$ by (a) two active heaters and $(b)$ four active heaters. The liquid is not removed. The yellow rectangles identify the locations of the active heaters before they are raised.
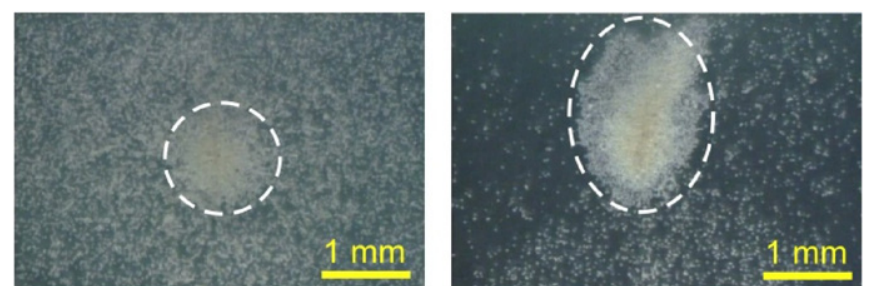

(a) DC-550
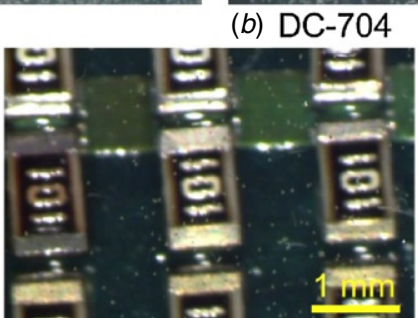

(c) FC-3283

Figure 6. Particle sedimentation in three different liquids. (a) Sedimentation in silicone oil DC-550. Particle collection is limited to a small area below the heater. $(b)$ Sedimentation in silicone oil DC-704. More particles are collected from a larger area to form a larger accumulation. $(c)$ No accumulation occurs in electronic liquid FC-3283. The suspended heater is not raised before taking the image.

area and higher concentration of particles is formed when a greater amount of particles are accumulated by the Marangoni cells. From equation (1), it is evident that higher temperature gradients at the liquid surface and lower viscosities produce higher flow velocities. Marangoni cells with high enough surface and subsurface velocities have the ability to transport particles from a larger area to form a bigger accumulation directly below the active heater(s). Comparing the two silicone oils, silicone oil DC-550 has surface tension temperature coefficient approximately twice that of silicone oil DC-704, and viscosity about three times that of silicone oil DC-704. The lower particle velocities in silicone oil DC-550 cause some particles transported by Marangoni cells to settle on the glass substrate before they come to a region below the active heater, so that the final pattern is not as focused as that obtained by silicone oil DC-704. The electronic liquid FC3283 has absolute viscosity two to three orders of magnitude lower; its thermal conductivity is also one order of magnitude lower than those of silicone oils. This favors the formation of a higher temperature gradient (the peak temperature gradient is $37 \mathrm{~K} \mathrm{~mm}^{-1}$ on the surface, about twice that of the silicone 
oils) and flow velocities in this liquid. When suspended particles move at high velocities away from the heat source and come in contact with the boundaries used to contain the liquid, some of these particles remain at the boundaries and are not recirculated by the subsurface flows to a region below the active heater. Different liquids also have different vapor pressures and thus evaporation rates, which may influence the final patterns of sedimentation. Although the vapor pressure of the electronic liquid FC-3283 is much higher than those of the silicone oils, the evaporative effects of the fluorinated liquid on sedimentation are not evident. The volume fraction of evaporation in the duration of one experiment is $<10 \%$. Effects of evaporation become apparent when a liquid having higher vapor pressure is used. Acetone, for example, has a vapor pressure one order higher than that of FC-3283. The high evaporation rate of acetone limits the formation of Marangoni cells as the experiment progresses, and particles are randomly deposited on the glass substrate as the liquid evaporates.

The use of the $16 \times 8$ heater array allows different configurations of active heaters to be used for different sedimentation patterns. When four corner heaters of a $3 \times$ 3 pixel array are activated, the final sedimentation on the glass substrate covers an area of approximately $28 \mathrm{~mm}^{2}$ in silicone oil DC-704. The sedimentation is not as focused as that obtained by the $2 \times 2$ pixel configuration shown in figure $5(b)$, because the deposited particles are now spread over a larger area. Activating four corner heaters of a $4 \times$ 3 pixel array produces an even more scattered rectangularshaped sedimentation covering an area of about $32 \mathrm{~mm}^{2}$ in silicone oil DC-704, with higher counts of particles at the four corners of the rectangular pattern.

It is worthwhile to compare the Marangoni forces that were utilized for particle collection in this effort, with some of the other approaches that have been reported. For example, thermophoresis is a method that uses temperature gradient to move particles. This method has been reported to form twodimensional colloidal crystals [32]. Although it is conceivable that thermophoretic forces may contribute to some extent to particle arrangements in the experiments described in the preceding section, the contribution is likely to be minor. Based on the particle transportation velocity, the Marangoni forces are on the order of $10^{-8} \mathrm{~N}$, whereas thermophoretic forces are on the order of $10^{-10} \mathrm{~N}$. This estimate uses Stokes' drag equation; particle velocities for Marangoni flow and thermophoresis are on the order of $1 \mathrm{~mm} \mathrm{~s}^{-1}$ and $10 \mu \mathrm{m} \mathrm{s}^{-1}$ [33], respectively.

One of the most widely explored methods for particle manipulation in microfluidic systems is dielectrophoresis (DEP) [34-36]. This method uses non-uniform electric fields applied to polarizable particles that are immersed in nonconductive liquid having polarization characteristics different from those of the particles. Typical utilization involves electrical lead transfer to electrodes that are located on the microfluidic chip. Typical forces that have been reported for DEP structures are in the range of $10^{-12}$ to $10^{-10} \mathrm{~N}$ [37]. Hence, the Marangoni technique is potentially a complementary technique to others that have been explored for use in microanalytical systems.
In conclusion, this study shows that a millimeter-sized heat source is able to generate Marangoni cells in the liquid films for the purpose of spatially localized sedimentation of small suspension particles such as weed pollen. Various sedimentation patterns can be produced on a blank substrate by a suspended 2D heater array, which is able to impose different temperature profiles on the liquid surface and consequently alter the surface and subsurface flows. Among the three liquids used, silicone oil DC-704 shows to be the best carrier liquid to obtain a focused sedimentation of the weed pollen. A localized sedimentation of area $2.9 \mathrm{~mm}^{2}$ directly below the heater is obtained when a single heater is activated to generate a liquid surface temperature rise of $6.9{ }^{\circ} \mathrm{C}$ in $1 \mathrm{~mm}$ deep silicone oil DC-704. When four heaters are activated, the area of the sedimentation obtained is about $7.9 \mathrm{~mm}^{2}$. Because this is a non-contact technique, the problem of contamination is eliminated. This method of directed deposition may have potential applications in environmental science and biology if temperature elevation is not a critical issue in the sedimentation process.

\section{Acknowledgments}

The authors thank Professor Amar Basu for the meaningful discussion, guidance in modeling, as well as the development of the 128 pixel heater array. EH is grateful for the graduate student fellowship support from the Department of Electrical Engineering and Computer Science of the University of Michigan, Ann Arbor.

\section{References}

[1] Yager P, Edwards T, Fu E, Helton K, Nelson K, Tam M R and Weigl B H 2006 Microfluidic diagnostic technologies for global public health Nature 442 412-8

[2] Pollack M G, Pamula V K, Srinivasan V and Eckhardt A E 2011 Applications of electrowetting-based digital microfluidics in clinical diagnostics Expert Rev. Mol. Diagn. 11 393-407

[3] Moon H-S, Nam Y-W, Park J C and Jung H-I 2009 Dielectrophoretic separation of airborne microbes and dust particles using a microfluidic channel for real-time bioaerosol monitoring J. Electrost. 67 89-92

[4] Scriven L E and Sternling C V 1960 The Marangoni effects Nature 187 186-8

[5] Nikolov A D, Wasan D T, Chengara A, Koczo K, Policello G A and Kolossvary I 2002 Superspreading driven by Marangoni flow Adv. Colloid and Interface Sci. $96325-38$

[6] Lappa M 2005 Review: possible strategies for the control and stabilization of Marangoni flow in laterally heated floating zones Fluid Dyn. Mater. Process. 1 171-87

[7] Lai C-L and Chai A-T 1986 Surface temperature distribution along a thin liquid layer due to thermocapillary convection Acta Astronaut. 13 655-9

[8] Lu H-H, Yang Y-M and Maa J-R 1996 Effect of artificially provoked Marangoni convection at a gas/liquid interface on absorption Ind. Eng. Chem. Res. 35 1921-8

[9] D'Aubeterre A, Da Silva R and Aguilera M E 2005 Experimental study on Marangoni effect induced by heat and mass transfer Int. Commun. Heat Mass Transfer 32 677-84 
[10] $\mathrm{Hu} \mathrm{H}$ and Larson R G 2005 Analysis of the effects of Marangoni stresses on the microflow in an evaporating sessile droplet Langmuir 21 3972-80

[11] Hu H and Larson R G 2006 Marangoni effect reverses coffee-ring depositions J. Phys. Chem. B 110 7090-4

[12] Tadmor R 2009 Marangoni flow revisited J. Colloid Interface Sci. 332 451-4

[13] Bhardwaj R, Fang X and Attinger D 2009 Pattern formation during the evaporation of a colloidal nanoliter drop: a numerical and experimental study New J. Phys. 11075020 (33 pp)

[14] Kaminsky V A, Vyaz'min A V, Kulov N N and Dil'man V V 1998 Marangoni effect in the presence of bulk turbulence Chem. Eng. Sci. 53 3347-53

[15] Rongy L and De Wit A 2007 Marangoni flow around chemical fronts traveling in thin solution layers: influence of the liquid depth J. Eng. Math. 59 221-7

[16] Anderson J L 1989 Colloid transport by interfacial forces Annu. Rev. Fluid Mech. 21 61-99

[17] Würger A 2007 Thermophoresis in colloidal suspensions driven by Marangoni forces Phys. Rev. Lett. 98 138301-1-4

[18] Farahi R H, Passian A, Ferrell T L and Thundat T 2004 Microfluidic manipulation via Marangoni forces Appl. Phys. Lett. 85 4237-9

[19] Selva B, Miralles V, Cantat I and Jullien M-C 2010 Thermocapillary actuation by optimized resistor pattern: bubbles and droplets displacing, switching and trapping $L a b$ Chip 10 1835-40

[20] Basu A S and Gianchandani Y B 2008 Virtual microfluidic traps, filters, channels and pumps using Marangoni flows J. Micromech. Microeng. 18115031 (11 pp)

[21] Basu A S and Gianchandani Y B 2009 A programmable array for contact-free manipulation of floating droplets on featureless substrates by the modulation of surface tension J. Microelectromech. Syst. 18 1163-72

[22] Hendarto E and Gianchandani Y B 2010 Directed precipitation of suspension particles onto blank substrates using Marangoni cells The 14th Int. Conf. on Miniaturized Systems for Chemistry and Life Sciences (MicroTAS 2010) (Groningen, The Netherlands) pp 1100-2

[23] Basu A S and Gianchandani Y B 2007 Shaping high-speed Marangoni flow in liquid films by microscale perturbations in surface temperature Appl. Phys. Lett. 90 034102-1-3

[24] Higuera F J 2000 Steady thermocapillary-buoyant flow in an unbounded liquid layer heated uniformly from above Phys. Fluids 12 2186-97

[25] 1998 Product information on Dow Corning 702, 704, 705 fluids, Dow Corning Corporation, Midland, MI, USA

[26] 1998 Product information on Dow Corning 550 fluid, Dow Corning Corporation, Midland, MI, USA

[27] 2001 Product information on Fluorinert ${ }^{\mathrm{TM}}$ Electronic Fluid FC-3283, 3M Specialty Materials, St Paul, MN, USA

[28] Eötvös R 1886 Ueber den Zusammenhang der Oberflächenspannung der Flüssigkeiten mit ihrem Molecularvolumen Ann. Phys. 263 448-59

[29] 2010 Product information on P9770 — weed pollens from Kochia scoparia (firebush), Sigma-Aldrich, St Louis, MO, USA

[30] Di-Giovanni F, Kevan P G and Nasr M E 1995 The variability in settling velocities of some pollen and spores Grana 34 39-44

[31] Sosnoskie L M, Webster T M, Dales D, Rains G C, Grey T L and Culpepper A S 2009 Pollen grain size, density and settling velocity for Palmer amaranth (Amaranthus palmeri) Weed Sci. 57 404-9

[32] Duhr S and Braun D 2005 Two-dimensional colloidal crystals formed by thermophoresis and convection Appl. Phys. Lett. 86 131921-1-3

[33] Duhr S, Arduini S and Braun D 2004 Thermophoresis of DNA determined by microfluidic fluorescence Eur. Phys. J. E 15 277-86

[34] Gascoyne P R C and Vykoukal J 2002 Particle separation by dielectrophoresis Electrophoresis 23 1973-83

[35] Zhang C, Khoshmanesh K, Mitchell A and Kalantar-Zadeh K 2010 Dielectrophoresis for manipulation of micro/nano particles in microfluidic systems Anal. Bioanal. Chem. 396 401-20

[36] Voldman J 2006 Electrical forces for microscale cell manipulation Annu. Rev. Biomed. Eng. 8 425-54

[37] Wang X-B, Huang Y, Gascoyne P R C and Becker F F 1997 Dielectrophoretic manipulation of particles IEEE Trans. Ind. Appl. 33 660-9 